\title{
Medical Applications in Everyday Surgical Practice
}

\author{
Kripouri Panagiota, Grevenitis Konstantinos, Filippou Dimitrios
}

\begin{abstract}
Technological evolution has lead to great inventions and smart phones are certainly one. This perception article investigates the possible advantages and disadvantages of using smart phone applications in different surgical subspecialties. Since phones can now store a huge amount of data and can send and receive multimedia such as video and sound these applications could benefit surgeons not only in terms of telemedicine but also as an educational or decision-making tool. However, such applications raise some significant ethical questions for the surgeon.
\end{abstract}

Index Terms - Medical applications, mobiles, surgery, m-health

\section{INTRODUCTION}

Medicine has undergone a revolution in the last two hundred years; the evolution of technology has lead to the invention of the mobile phone which in the latest years has become increasingly light and easy to carry around. This breakthrough resulted in smartphones which offered the capability to share data like photos or videos easily, exchange e-mails and receive voice mails with numerous possibilities in terms of telemedicine. Nowadays, mobile phones have become more accessible and have taken over a large piece of our everyday life. Could this technological advance help modernize medicine and especially surgery? If so, which surgical subspecialties would benefit the most?

\section{MEDICAL APPLICATIONS IN SURGICAL SUBSPECIALITIES AND PREOPERATIVE MEDICINE}

\section{A. Preoperative medicine and Anesthesiology}

Any reference to the applications of smart phones to surgery would be incomplete without mentioning the numerous applications for anesthesiology. Smart phones and small devices are if connected to proper probs a useful tool as they can be used as emergency ultrasounds and monitors and even as educational appliances for the patient, since educational

Kripouri Panagiota, Postgraduate Student, Department of Anatomy and Surgical Anatomy, Medical School, National and Kapodistrian University of Athens, Athens, Greece

Grevenitis Konstantinos, Postgraduate Student, Department of Applied Informatics, University of Macedonia, Thessaloniki, Greece

Filippou Dimitrios, Chief Surgeon, Department of Anatomy and Surgical Anatomy, Medical School, National and Kapodistrian University of Athens, Athens, Greece

Corresponding Author; Kripouri Panagiota, MD, 80 Mesogion Avenue, GR-11527 Ampelokipi, Athens, Greece games can be used to train the patient before the procedure for example in order to make life style changes such as lose some weight. [1] In the same study it has been stated that such applications could be used not only in the hospital setting but also in home monitoring. Moreover, it has been suggested that the use of such devices could even help retrospective data analysis because they do collect data constantly during the operation which could not be done by handwritten anesthesiologist's notes or monitor reports only. [2]

\section{B. General Surgery and orthopedics}

In the vast field of general surgery medical mobile apps could offer a great help. They could facilitate the intra operative imaging, surgeons and hospitals communicate the patient's history and exams and they could even be used as a surgeon's archive for completed surgeries. [3] In bariatric surgery an older review showed that applications serve a variety of goals including patient's education, experience sharing, centers advertising and applications designed for academic use and authors implied that doctors' involvement in the assessment of the information presented in those applications is necessary in order to ensure their credibility. [4] While in orthopedics mobiles also help prepare the patient for the procedure they can also train the resident in radiology and anatomy via images and video footage and keep them informed about medical conferences. [5]

\section{In urology and other surgical subspecialties}

In a 2015, 42 apps related to kidney stones were identified with the great majority of them being designed for patients and not doctors. However, a $10 \%$ of those 42 mobile apps were referring to herbal remedies and none of them had any indication that medical personnel were involved in assessing the information presented. Additionally, $21 \%$ out of the total were designed for doctors and doctors' involvement in those was apparent. [6] When not only kidney stone related urology applications were identified, out of 129 apps the results were also disappointing: 19,4\% of the apps were designed without health care personnel involvement. Authors of this review addressed the necessity for regulation by healthcare authorities.[7]

There are many apps used in plastic surgery for educational, academic or entertainment purposes. There are atlases mobile versions, academic database apps and anatomy apps to facilitate studying and research by students and residents. [8] Some patient-targeted apps enable the person to upload their photos and explore the possible outcome after plastic surgery however this may have a negative result on having realistic anticipations. [9] Especially in plastics, serious games designed for kids or even health care providers can help 
spread the knowledge about burns and their treatment. There are also medical calculators to use when treating burns; however use with caution is advised. [10] Likewise in cardiothoracic apps are used to calculate, diagnose or get educated, while otolaryngology and maxillofacial and neurosurgery could be no exception. [11], [12], [13]

\section{ETHICAL CONSIDERATIONS}

Medical applications make everyday practice easier; they can take over writing patient's record, archiving examination results and even keeping track of what happened in the operation room by collecting data during surgery. This could be time saving and help increase efficacy. However, what if all of these data fell into the wrong hands? It has been stated that a scenario in which a pharmaceutical company would be involved in the making of such an app would be quite dystopic [14] but what about a insurance company having access to all the patient's medical information? Regulating medical applications can be proven especially difficult although efforts have been made. [15]

\section{CONCLUSION}

Medical applications are a tool in the modern doctor's hands. Like every other tool (even the scalpel) they can be used as a helpful assistance or a lethal weapon. Since medicine evolves rapidly, authors of this article suggest that medical students and residents should be familiar with the new technology and be able to use it whenever possible. However, they should be educated to avoid being based on the technology alone and they should have the clinical skills to sufficiently diagnose, treat and monitor the patient even when such devices are not around. Moreover, young doctors should be able to think critically and protect the patients' rights and should be confronted with ethical dilemmas during their training the authors suggest.

\section{REFERENCES}

[1] Michard F. Smartphones and e-tablets in perioperative medicine. Korean J Anesthesiol. 2017 Oct;70(5):493-499.

[2] Pybus DA. Expanding the role of mobile devices in the operating room: direct wireless connection to the anesthesia monitor. J Cardiothorac Vasc Anesth. 2015;29(3):785-90.

[3] Warnock GL. The use of apps in surgery. Canadian Journal of Surgery. 2012;55(2):77.

[4] Stevens DJ, Jackson JA, Howes N, Morgan J. Obesity surgery smartphone apps: a review. Obes Surg. 2014 Jan;24(1):32-6.

[5] Popat R, Mohan AT, Branford OA. Current uses of smartphones and apps in orthopaedic surgery. Br J Hosp Med (Lond). 2013 Dec;74(12):672-6.

[6] Stevens DJ, McKenzie K, Cui HW, Noble JG, Turney BW. Smartphone apps for urolithiasis. Urolithiasis. 2015 Feb;43(1):13-9.

[7] Pereira-Azevedo N, Osório L, Cavadas V, Fraga A, Carrasquinho E, Cardoso de Oliveira E, Castelo-Branco M, Roobol MJ. Expert Involvement Predicts mHealth App Downloads: Multivariate Regression Analysis of Urology Apps. JMIR Mhealth Uhealth. 2016 Jul 15;4(3):e86.

[8] Al-Hadithy N, Ghosh S. Smartphones and the plastic surgeon. J Plast Reconstr Aesthet Surg. 2013 Jun;66(6):e155-61. doi: 10.1016/j.bjps.2013.02.014.

[9] Mohan AT, Branford OA. iGuide to plastic surgery: iPhone apps, the plastic surgeon, and the health care environment. Aesthet Surg J. 2012 Jul;32(5):653-8.

[10] Wurzer P, Parvizi D, Lumenta DB, Giretzlehner M, Branski LK, Finnerty CC, Herndon DN, Tuca A, Rappl T, Smolle
C, Kamolz LP. Smartphone applications in burns. Burns. 2015 Aug;41(5):977-89.

[11] Edlin JC, Deshpande RP. Caveats of smartphone applications for the cardiothoracic trainee. J Thorac Cardiovasc Surg. 2013 Dec;146(6):1321-6.

[12] Wong MC, Fung K. Mobile applications in otolaryngology-head and neck surgery. Otolaryngol Head Neck Surg. 2015 Apr;152(4):638-43.

[13] Robertson GAJ, Wong SJ, Brady RR, Subramanian AS. Smartphone apps for spinal surgery: is technology good or evil? Eur Spine J. 2016 May;25(5):1355-1362.

[14] Krieger WH. Medical apps: public and academic perspectives. Perspect Biol Med. 2013 Spring;56(2):259-73.

[15] Carter A, Liddle J, Hall W, Chenery H. Mobile Phones in Research and Treatment: Ethical Guidelines and Future Directions. Eysenbach G, ed. JMIR mHealth and uHealth. 2015;3(4):e95. doi:10.2196/mhealth.4538. 